\title{
MOTIVAÇÕES DE PEQUENOS ECOEMPREENDEDORES PARA CRIAREM NEGÓCIOS SUSTENTÁVEIS NO SETOR DE TURISMO - UM ESTUDO MULTICASO NA REGIÃO METROPOLITANA DE CURITIBA
}

\author{
MOTIVATIONS OF SMALL ECO-ENTREPRENEURS TO CREATE \\ SUSTAINABLE BUSINESS IN THE TOURISM SECTOR - A \\ MULTICASE STUDY IN THE METROPOLITAN REGION OF \\ CURITIBA-PR
}

\section{MOTIVACIONES DE PEQUEÑOS ECOEMPREENDEDORES PARA CREAR NEGOCIOS SOSTENIBLES EN EL SECTOR DE TURISMO - UN ESTUDIO MULTICASO EN LA REGIÓN METROPOLITANA DE CURITIBA-PR}

VIVIEN KANIAK

Doutoranda em Administração pela Universidade Federal do Paraná (UFPR) vivikaniak@gmail.com http://orcid.org/0000-0003-1410-8592

RIVANDA MEIRA TEIXEIRA

Doutora em Administração pela Cranfield University

Professora associada do Programa de Pós-Graduação em Administração da Universidade Federal do Paraná (UFPR)

rivandateixeira@gmail.com

http://orcid.org/0000-0003-3056-6032

\section{DATA DE SUBMISSÃO: 01/04/2018 - DATA DE ACEITE: 24/07/2018}

RESUMO: Os pequenos ecoempreendedores representam uma relevante parte dos empresários que atuam no setor de turismo na natureza, no espaço rural e com ecoturismo, gerando desenvolvimento econômico e social e, ao mesmo tempo, atuando na preservação do meio ambiente. Embora os estudos sobre o empreendedorismo sustentável tenham crescido nos últimos anos, constata-se que ainda são poucos os que enfocam as motivações dos ecoempreendedores que atuam nestes setores do turismo. O objetivo central desta pesquisa foi analisar as motivações de ecoempreendedores com base nas tipologias de Walley \& Taylor (2002). A metodologia utilizada foi qualitativa e exploratória e a estratégia de pesquisa foi a de estudos de multicasos. Participaram do estudo cinco ecoempreendedores da região metropolitana de Curitiba-PR e o principal instrumento de coleta de evidências foi a entrevista semiestruturada. Os resultados apontam que os entrevistados possuem um forte direcionamento para a sustentabilidade, cujos valores verdes estão presentes nos seus negócios e que também direcionam as suas práticas. Além desses valores, esses ecoempreendedores iniciaram ou mantêm o negócio como forma de assegurar seu estilo de vida que envolve, entre outras coisas, uma alimentação natural, o desejo de viver longe da cidade grande e a preservação do meio ambiente.

Licença CC BY: Artigo distribuído sob os termos e Commons, permite uso e distribuição irrestrita em qualquer meio desde que o autor credite a fonte original.

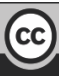


PALAVRAS-CHAVE: Ecoempreendedorismo. Turismo na natureza. Motivação de empreendedores.

ABSTRACT: Small eco-entrepreneurs represent a relevant portion of entrepreneurs who work in the natural tourism sector, rural locations and ecotourism, generating economic and social development and, at the same time, acting in the preservation of the environment. Although studies on sustainable entrepreneurship have grown in recent years, there are still few that focus on the motivations of ecoentrepreneurs working in the tourism sector. The central objective of this research was to analyze the motivations of eco-entrepreneurs, based on the typologies of Walley \& Taylor (2002). The methodology used was qualitative and exploratory and the research strategy consisted of multicase studies. Five ecoentrepreneurs from the Curitiba-PR metropolitan region participated in the study, and the main evidencegathering instrument was a semi-structured interview. The results indicate that the interviewees have a strong orientation towards sustainability; green values are present in their businesses, and also guide their practices. In addition to these values, these eco-entrepreneurs started or maintain their business as a way to ensure their lifestyle, which involves, among other things, a natural diet, the desire to live away from the big city, and preservation of the environment.

KEYWORDS: Ecoentrepreneurship. Natural tourism. Entrepreneurs motivation.

RESUMEN: Los pequeños ecoemprendedores representan una parte relevante de empresarios que operan en el sector turismo comprometidos con la naturaleza, el espacio rural y con el ecoturismo. De esta manera generan desarrollo económico y social, asimismo, actúan en la preservación del medio ambiente. Aunque los estudios sobre emprendedorismo sostenible han aumentado en los últimos años, se constata que aún son pocos los que se enfocan en las motivaciones de los ecoemprendedores que actúan en el sector de turismo. El objetivo central de esta investigación fue analizar las motivaciones de los ecoemprendedores, teniendo como base las tipologías de Walley \& Taylor (2002). La metodología utilizada fue cualitativa y exploratoria, y la estrategia de investigación fue la de estudio de multicasos. Participaron en el estudio cinco ecoemprendedores de la región metropolitana de Curitiba-PR y el principal instrumento de recolección de evidencias fue la entrevista semiestructurada. Los resultados demuestran que los entrevistados están fuertemente direccionados por la sustentabilidad, cuyos valores verdes están presentes en sus negocios y orientan sus prácticas. Además de esos valores, los ecoemprendedores iniciaron o mantienen sus negocios como forma de asegurar sus estilos de vida que involucran, entre otras cosas, una alimentación natural, el deseo de vivir lejos de la gran ciudad y la preservación del medio ambiente.

\section{INTRODUÇÃO}

No cenário global atual, em que são buscadas alternativas para preservação da natureza, a criação de negócios sustentáveis dá suporte ao crescimento da economia, além de resultar na melhora da qualidade de vida e na redução de riscos ecológicos (Anup, Rijal, \& Sapkota, 2015). O empreendedorismo sustentável é um tema que vem sendo abordado por pesquisas nos últimos anos com ênfase em questões organizacionais, financeiras, políticas, ecológicas, entre outras (Isaak, 2002, Koe, \& Majid, 2014, Mieszajkina, 2016, Pastakia, 1998, Schaltegger, 2002). Entretanto é importante salientar que empreendedorismo sustentável não é sinônimo de ecoempreendedorismo, uma vez que o último objetiva atuar em questões ecológicas; enquanto o primeiro é muito mais amplo e engloba o sustento de comunidades e desenvolvimento para indivíduos e sociedade (Shepherd \& Patzelt, 2011). Embora a literatura sobre pequenas empresas atuando em atividades sustentáveis tenha aumentado nas últimas décadas, ainda existem poucos estudos sobre quem é o ecoempreendedor que cria e gerencia essas empresas (Borges, Borges, Ferreira, Najberg, \& Tete, 2013, Kirkwood \& 
Walton, 2010, Shepherd \& Patzelt, 2011, Walley \& Taylor, 2002). Por este motivo, estudar o perfil e as motivações de ecoempreendedores é crítico para o desenvolvimento e progresso do turismo, pois ele é um dos principais agentes para promover um futuro mais sustentável no setor (Budeanu, Miller, Moscardo, \& Ooi, 2016).

Neste contexto, o ecoempreendedor assume um papel de destaque como a figura central para encontrar soluções para a degradação ambiental (Parrish, 2010, Shepherd \& Patzelt, 2011, York \& Venkataraman, 2010), ao contrário dos empreendedores de motivação puramente econômica ou capitalista, típicos das décadas anteriores. Nas pesquisas existentes, os empreendedores verdes têm sido caracterizados de acordo com certas tipologias que, por sua vez, são reconhecidos por meio de suas motivações para iniciar ou se manter no negócio (Gibbs, 2009, Swan \& Morgan, 2016). Este estudo utilizou o modelo de tipologias de Walley \& Taylor (2002) como ferramenta para analisar o perfil, as influências e os motivadores dos empreendedores verdes na área do turismo. O modelo dos autores foi escolhido por ter sido construído dentro de uma concepção sociopsicológica que engloba além do nível de análise do indivíduo para envolver também uma análise do contexto do empreendimento dentro de uma abordagem sociológica e econômica. A abordagem sociopsicológica tem como pressuposto o estudo das características do empreendedor como fruto de uma interação entre personalidade e outros fatores como experiências passadas, competências existentes e contexto (Anderson, 1998, Kirkwood \& Walton, 2010).

Esse estudo foi realizado em pequenas empresas do setor de turismo. O setor de turismo vem apresentando crescimento contínuo ao longo das últimas décadas e é um dos setores de mais rápido crescimento no mundo. Atualmente o volume de negócios em turismo equivale à exportação de petróleo, produtos alimentares e automóveis, tendo chegado a U\$1,2 bilhões em 2016 e tendo contribuído com 10\% do PIB mundial, além de ser responsável por 1 a cada 10 empregos ao redor do mundo (World Tourism Organization, 2018). No Brasil, os gastos de turistas chegaram a 6 milhões em 2016, sendo que o turismo respondeu por 9 milhões de empregos diretos e indiretos no país (Ministério do Turismo, 2018). O ecoturismo, como componente da economia verde, é um dos segmentos da indústria turística com crescimento mais rápido atualmente e tem seu foco na conservação ambiental e no desenvolvimento social, com geração de progresso econômico e empregos (Anup et al., 2015, Hall, Daneke, \& Lenox, 2010, Jones \& Spadafora, 2016, Lordkipanidze, Brezet, \& Backman, 2005, Swan \& Morgan, 2016). Desta forma, justifica-se a importância deste estudo ao ampliar a escassa literatura existente sobre as principais motivações que levam os pequenos ecoempreendedores a se dedicarem ao turismo na natureza em ambiente rural.

O objetivo geral foi investigar as motivações dos ecoempreendedores baseado na tipologia de Walley \& Taylor (2002) para investir na área. Especificamente buscouse caracterizar as pequenas empresas atuantes no setor, delinear o perfil desses ecoempreendedores, identificar as suas motivações para criar negócios ecologicamente sustentáveis, verificar o impacto desses negócios na comunidade e, finalmente, a sua percepção de lucro.

Espera-se que esta pesquisa traga contribuições acadêmicas ao discutir a temática do empreendedorismo sustentável, analisando as motivações dos empreendedores que atuam no setor de turismo de natureza em ambiente rural. Em termos práticos, espera-se que possa oferecer subsídios para que se criem e promovam estratégias de desenvolvimento de negócios 
ambientalmente sustentáveis e para orientar e impulsionar novos ecoempreendedores para investir levando em conta a preservação e a manutenção do meio ambiente.

\section{FUNDAMENTAÇÃO TEÓRICA EMPREENDEDORISMO SUSTENTÁVEL}

De acordo com Schaltegger \& Wagner (2011), o empreendedorismo sustentável foi se modificando de modo a englobar não somente o desenvolvimento das organizações, mas para contribuir de forma mais ampla para a sustentabilidade da sociedade. Tal conceito foi se fortalecendo à medida que os efeitos negativos da industrialização no meio ambiente, como diminuição da camada de ozônio, mudanças climáticas, degradação dos ecossistemas, foram aumentando e impactando as pessoas e os governos (Elmuti, Abebe, \& Nicolosi, 2005, Hall et al., 2010). O empreendedorismo sustentável é, portanto, um tema de pesquisa relativamente novo, que nasceu de um esforço para conectar os campos de conhecimento do empreendedorismo e da sustentabilidade, emergindo de estudos sobre negócios, meio ambiente e responsabilidade social (Boszczowski \& Teixeira, 2012). Ao analisar estudos realizados na presente década, observa-se que o empreendedorismo sustentável é tratado como variados tipos de negócios: a) os que unem questões ambientais, sociais e econômicas e criam vantagem competitiva; b) os que estão voltados para uma causa social, embora gerem lucro e possam integrar questões ambientais em seus processos ou produtos; c) os que focam na causa ambiental e, finalmente, d) as empresas que possuem práticas de sustentabilidade que geram benefícios sociais ou ambientais, porém não os têm como foco principal de seus negócios (Brunelli \& Cohen, 2012, Dixon \& Clifford, 2007, Hall et al., 2010).

\section{ECOEMPREENDEDORISMO}

Como já citado, o ecoempreendedorismo ou empreendedorismo verde são uma forma de empreendedorismo praticada por empreendedores que encontraram novos negócios baseados nos princípios de sustentabilidade (Kirkwood \& Walton, 2010, Prochnow \& Vasconcelos, 2008, Swan \& Morgan, 2016). Em relação ao conceito de empreendedor verde ou ecoempreendedor (que serão tomados como sinônimos neste estudo), está ligado aos indivíduos que ganham seu sustento por meio de uma atividade de negócios financeiramente orientada, os quais fundaram ou estabeleceram um empreendimento no nicho verde e que produzem intencionalmente mais do que consomem para gerar lucro com a atividade (Walley \& Taylor, 2002).

De acordo com Schaltegger (2002), o termo ecoempreendedor é a combinação das palavra "eco", que vem de "ecológico", e "empreendedorismo". Para o autor, o ecoempreendedorismo é "o empreendedorismo visto através das lentes do meio ambiente". Mais tarde ele amplia o conceito e classifica dois tipos de empreendedores: o empreendedor sustentável, que possui motivação de resolver problemas sociais e ambientais por meio de um negócio de sucesso; e o empreendedor ambiental, que deseja contribuir para resolver um problema ambiental enquanto gera lucro (Schaltegger \& Wagner, 2011). Tal qual apontado por Brunelli \& Cohen (2012), a literatura apresenta muitas vezes os conceitos de empreendedorismo ambiental, ecoempreendedorismo e empreendedorismo verde como 
sinônimos. Para fins deste estudo, serão enfocados os empreendedores que possuem tanto a motivação econômica, ao criar seus negócios, quanto o desejo de diminuir os problemas no meio ambiente.

Gast, Gundolf, \& Cesinger (2017), que realizaram recentemente uma revisão sistemática de literatura sobre empreendedorismo sustentável ecológico, afirmam que muitos são os conceitos e rótulos que tentam conectar a área, tais como: eco empreendedorismo, empreendedorismo ambiental e empreendedorismo verde. Todos se baseiam em empreendedores e negócios que têm por atividade a sustentabilidade, os princípios verdes e são amigáveis ao meio ambiente. Os referidos autores definiram empreendedorismo sustentável ecológico como o processo de identificar, avaliar e aproveitar oportunidades empreendedoras que minimizem o impacto do risco no meio ambiente e assim crie benefícios para a sociedade e para a comunidade local. De todo modo, vários os autores convergem que ecoempreendedores procuram combinar consciência ambiental com negócios de sucesso e atividades empreendedoras, são proativos e ecologicamente orientados (Gibbs, 2009, Isaak, 2002, Mieszajkina, 2016).

\section{O ECOEMPREENDEDOR: MOTIVAÇÕES E TIPOLOGIAS}

Apesar de existirem muitos estudos sobre motivações para empreender de forma geral, ainda são poucos os relacionados às motivações dos ecoempreendedores para criarem negócios sustentáveis (Kirkwood \& Walton, 2010). Várias tipologias sobre motivações de ecoempreendedores foram propostas, embora existam variações consideráveis entre elas (Kirwood \& Walton, 2008). Schaltegger (2002) propôs uma tipologia com cinco tipos de ecoempreendedores: a) alternative actors: quando o negócio existe para apoiar um estilo de vida e objetivos de mercado não são tão importantes, as melhorias ambientais são limitadas. b) Bioneers: ocupam nichos de mercado de tamanho médio, são inventores com forte foco em P\&D e geralmente atuam em setores de alta tecnologia; c) ecopreneurs: buscam possuir uma maior porção do mercado, não são inventores, mas identificam potencial de mercado em invenções para produtos e serviços que resolvam problemas ambientais; d) environmental administrators: possuem forte foco administrativo, visam à correta implementação de instruções e procedimentos, a proteção ambiental é vista como um dever que deve ser gerenciado por causa de fatores externos (leis, mercado ou pressões sociais); e) environmental managers: há uma postura mais ativa para lidar com os problemas ambientais, a fim de ganhar vantagem competitiva para a empresa.

Linnanen (2002) também estudou os ecoempreendedores e os classificou em dois critérios principais: o desejo de mudar o mundo e o desejo de ganhar dinheiro. A partir dessa classificação, criou uma matriz de alto/baixo em relação à combinação das categorias, resultando em quatro tipos de ecoempreendedores: a) self-employer: são empreendedores que desejam ser diferentes do modelo capitalista. São satisfeitos com um nível de fluxo de caixa suficiente para garantir seu padrão de vida; b) non-profit business: desejam mudar a sociedade, mas não desejam crescer, os limites e as semelhanças com uma ONG não são claramente definidos; c) oportunists: normalmente têm experiência em indústria, expandindo para ecobusiness para criar lucro e são motivados por lucro e não valores; d) successful idealist: encontram equilíbrio entre ganhar dinheiro e fazer o mundo melhor, possuem forte 
desejo de mudar o mundo e são impulsionados a criar novos mercados, construindo assim um círculo virtuoso.

Kirwood \& Walton (2008) apontaram cinco grandes motivadores: a) valores verdes: empreendedores que combinam seus valores com percepções de lacunas no mercado, mantendo uma atividade sustentável; b) ganhar o sustento: empreendedores cuja motivação principal é ganhar o sustento; c) paixão: além de seus valores verdes, alguns empreendedores declaram possuir verdadeira paixão pela área de negócio, o que os motivou a seguir com o empreendimento; d) ser seu próprio chefe: esta foi a motivação de outro grupo de empreendedores que havia ou não trabalhado como empregados no passado; e) percepção de lacuna no mercado: alguns empreendedores entrevistados pelos autores apontaram lacunas percebidas, a partir disso iniciaram um negócio para preenchêlas. Os autores citados também apontam que os ecoempreendedores verdes têm motivações similares aos empreendedores em geral, mas diferem no que se refere aos valores verdes e possuem menor motivação financeira. Por sua vez, Swan \& Morgan (2016) apontam como motivações para empreender a criação de um estilo de vida idealizado o desejo de autonomia no trabalho, a promoção de um meio ambiente sustentável e o incentivo a práticas culturais, além do desejo econômico.

Este estudo utilizará como base a tipologia de Walley \& Taylor (2002), que classifica os empreendedores de acordo com "tipos". Esta ferramenta possui a vantagem de que as categorias não são mutuamente excludentes, isto é, um ecoempreendedor pode, em tese, ser caracterizado em mais de um dos 4 tipos, de acordo com a combinação de seus atributos.

Para criar sua tipologia, Waley \& Taylor (2002) fizeram inicialmente uma revisão das tipologias de empreendedorismo existentes na época e selecionaram as que eram mais relevantes para desenvolver uma tipologia de empreendedores verdes. Nesta seleção, os modelos de Thompson (1999), Dana (1995) e a definição de "green-green business" de Isaak (1998) são a base fundamental das tipologias propostas por Walley \& Taylor (2002).

De acordo com esses autores e para fins desta pesquisa, será utilizada a definição de negócios verdes como empreendimentos fundados nos princípios da sustentabilidade e o conceito de empreendedor verde como um indivíduo que fundou ou estabeleceu um negócio no nicho verde. Assim, parte-se do pressuposto que tais empreendedores têm, em alguma escala, objetivos de maximização de lucros. Portanto, este modelo de tipologia não abarca o setor sem fins lucrativos, embora se atesta que muitas vezes o empreendedor verde também tem motivações ético-sociais. Deste modo, todos os tipos de empreendedores verdes considerados contribuem para uma sociedade mais sustentável, já que são agentes de mudança fundamentais. Na visão dos Walley \& Taylor (2002), as variáveis mais importantes para caracterizar os empreendedores verdes são a motivação para mudar as estruturas da sociedade atuais (que variam de leve à forte) e a motivação de empreender (que varia de uma orientação puramente econômica a uma orientação para a sustentabilidade), criando desta forma quatro grandes tipos de empreendedores verdes de acordo com sua posição nos eixos horizontal e vertical, conforme pode ser visualizado na Figura 1. 


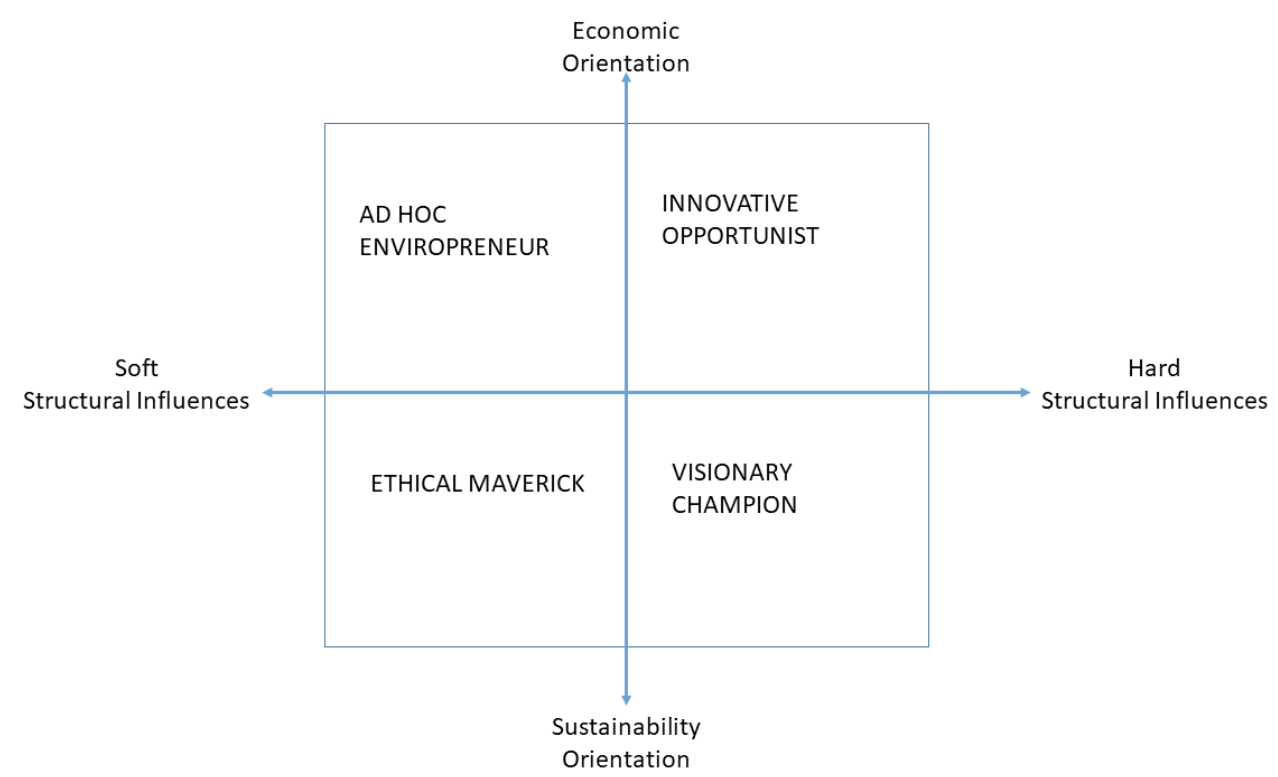

Figura 1. Tipologia dos empreendedores verdes Fonte: Walley, Taylor (2002)

No quadrante de cima à direita, encontra-se o tipo de empreendedor chamado pelos autores de Innovative Opportunist, que é fortemente orientado economicamente e vislumbrou uma oportunidade verde. Este tipo de empreendedor iniciou no nicho por possuir forte motivação estrutural, tal como uma nova legislação que o forçou ou levou a criar um produto ou processo com determinada especificação ecológica ou ambiental. No campo abaixo, encontra-se o Visionary Champion, que corresponde a um empreendedor envolvido com uma transformação de orientação sustentável. O objetivo dele é mudar o mundo, com uma visão de sustentabilidade futura que visa a uma transformação radical nas estruturas vigentes. No quadrante de baixo, à esquerda, observa-se o chamado Ethical Maverick, que é um tipo de empreendedor verde de leve motivação para mudar as estruturas, porém com forte direcionamento sustentável. No geral, este tipo de empreendedor teve por influência para montar o negócio a opinião de amigos, de uma rede de relações ou experiências pessoais passadas e mantém o foco do negócio para manter seu estilo de vida. Finalmente o quarto e último tipo, intitulado Ad Hoc Enviropreneur, é o empreendedor acidental, que foi levado a explorar o nicho verde muito mais por motivações financeiras que por valores pessoais e com pouco ou nenhum desejo de mudar o mundo ou as estruturas vigentes.

É importante salientar que os autores destacam que esse modelo de tipologia não deve ser rígido, já que é próprio dos empreendedores reinventarem seus negócios ao longo do tempo, de modo que é possível observar alguma movimentação entre um tipo e outro. Tampouco não é o objetivo dos autores propor um modelo de tipologias para enrijecer ou limitar o empreendedor em um tipo ideal, mas servir de ferramenta para a melhor compreensão dos aspectos ligados à motivação destes profissionais.

\section{O TURISMO NA NATUREZA, O TURISMO RURAL E O ECOTURISMO}

O turismo na natureza engloba a atividade turística destinada ao contato com a natureza, a vivência em ambientes tranquilos, a aproximação com a fauna e a flora, além da 
oportunidade de contato com uma nova experiência longe dos grandes centros urbanos (Gorni \& Dreher, 2010). Galvão (2004) acrescenta que o turismo na natureza pode ser classificado como qualquer turismo realizado em espaço natural, seja em uma praia ou campo, e sua característica é que ele não está necessariamente baseado na conservação do meio. O turismo na natureza está relacionado a temáticas como o ecoturismo, o turismo de aventura, o turismo educacional, além de outras atividades realizadas ao ar livre (Bob McKercher, 2002, Viana \& Nascimento, 2009). Já o turismo rural é apontado por Bosetti \& Oliveira (2016) como atividade turística desenvolvida especificamente em meio rural, normalmente praticado em fazendas ou sítios que associa atividades como passeio a cavalo, carroça, banhos de rio ou cachoeira e que acaba relacionado ao ecoturismo de muitas maneiras.

Entretanto o ecoturismo, também chamado de turismo ecológico ou ambiental, destaca-se das outras modalidades devido ao seu comprometimento com a conservação do meio ambiente, por meio do contato com ambientes naturais, promovendo a proteção das áreas visitadas (Donohoe \& Needham, 2006, Spaolonse \& Oliveira, 2017). Esta se caracteriza como a modalidade mais sustentável de turismo na natureza (Viana \& Nascimento, 2009).

De acordo com Asadi \& Kohan (2011), o ecoturismo como indústria de baixo impacto se estabeleceu no final dos anos 60 e início da década de 70 a partir da crescente preocupação com o uso dos recursos naturais. A criação da Agenda 21 também foi essencial para o estabelecimento da sustentabilidade, sendo o mais extenso documento produzido pela Organização das Nações Unidas (ONU). Assim, surge a necessidade da valorização da cultura dos povos e da natureza, de modo que, chegar à sustentabilidade exige uma mudança não só na sociedade, mas na civilização em si. Outros eventos impulsionaram a representatividade do tema, como a primeira Conferência sobre Turismo Sustentável, em Lanzarote, nas Ilhas Canárias, realizado em 1995 pela ONU (Organização das Nações Unidas), em parceria com a UNESCO (Organização das Nações Unidas para a educação, a ciência e a cultura) (Brumatti, 2014).

O turismo na natureza, bem como o ecoturismo, pode trazer inúmeros benefícios para o desenvolvimento sustentável, da comunidade local e dos negócios, a partir da oportunidade de intercâmbio cultural, possibilidades educacionais e preservação do meio ambiente, além da criação de empregos (Asadi \& Kohan, 2011, Dixon \& Clifford, 2007, Pimentel et al., 2013). Iraldo, Testa, Lanzini \& Battaglia (2017) destacam em seu estudo o importante papel desempenhado pelas pequenas empresas nesse cenário a partir de suas ações pró meio ambiente, que terminam por auxiliar em sua competitividade. Assim, muitas cidades e regiões investem no ecoturismo e no turismo na natureza, visando diminuir o desemprego, a exclusão social e melhorar a renda da comunidade (Bosetti \& Oliveira, 2016). Mesmo assim, conforme coloca Budeanu et al. (2016), é necessário que os vários atores envolvidos neste processo façam adaptações, já que a própria sobrevivência e continuação da sociedade no futuro dependem do sucesso dessas ações.

No Brasil, o ecoturismo, como segmento na área do turismo, apresenta-se em ascensão devido à diversidade de riquezas naturais, do território extenso e do rico patrimônio históricocultural (Spaolonse \& Oliveira, 2017). Prochnow \& Vasconcelos (2008) apontam que a vastidão e a diversificação geográfica brasileira favorecem as atividades de ecoturismo e que se pode observar o crescimento desta oferta de serviços entre as agências turísticas no país. 


\section{METODOLOGIA}

Esta pesquisa apresenta-se como qualitativa, por ser o meio mais indicado para estudar campos do saber ainda em construção, bem como captar de forma aprofundada acerca da natureza do objeto em questão (Godoi, Bandeira-de-Melo, \& Silva, 2006). De acordo com Creswell (2010), são típicos da pesquisa qualitativa a coleta de dados no ambiente natural, o pesquisador como coletor dos dados e observador do comportamento dos entrevistados, a utilização de várias fontes de dados como documentos, observações e entrevistas, além, é claro, da possibilidade de investigação interpretativa. A estratégia de pesquisa utilizada foi o estudo de casos múltiplos que, seguindo as recomendações de Eisenhardt (1989), foi usado para dar maior robustez à pesquisa. Além disso, buscou-se a triangulação de evidências levantadas por meio de entrevistas semiestruturadas, observação participante e análise documental.

Inicialmente foi feito um levantamento pela internet de possíveis pequenos empreendedores que atuam na área do turismo rural e na natureza na região metropolitana de Curitiba. Buscou-se por ecoempreendedores que atuassem em diversos tipos de negócios relacionados ao turismo e que levassem em conta a conservação e a preservação do meio ambiente; a sustentabilidade e a responsabilidade/consciência ética. Em seguida, foram selecionados aleatoriamente 12 ecoempreendedores que estavam localizados em um raio de até $40 \mathrm{~km}$ da capital para conveniência das pesquisadoras que residem em CuritibaPR. Estes foram contatados por mensagem eletrônica e por telefone e, a partir do convite e da explicação dos objetivos do estudo, cinco retornaram aceitando participar da pesquisa. Eram proprietários de micro e pequenas empresas, localizadas na região metropolitana de Curitiba. As empresas que retornaram e aceitaram ser entrevistadas foram: um restaurante, um produtor de alimentos orgânicos/atividades de ecoturismo, uma pousada ecológica, uma loja de artesanato e uma agência de ecoturismo.

Os empreendedores foram entrevistados com base em um roteiro semiestruturado criado pelas autoras, tendo como referência teórica o modelo de tipologias desenvolvido por Walley \& Taylor (2002), a fim de conhecer as suas motivações para empreender. Os relatos da entrevista foram complementados com evidências coletadas a partir da observação direta nas empresas dos serviços oferecidos e da estrutura física. Além disso, foram coletados documentos fornecidos pelos entrevistadores, tais como fôlderes de divulgação e pesquisa na internet. As entrevistas foram gravadas, transcritas e submetidas à análise de conteúdo com base na perspectiva qualitativa de Bardin (2011), em que os elementos passam por préanálise de conteúdo, a fim de sistematizar as ideias dos entrevistados. Na presente pesquisa, o conteúdo coletado pode ser resumido nas seguintes categorias de análise: características da empresa, perfil dos entrevistados, motivações para criar o negócio, impacto do negócio na comunidade, bem como sua relação com o meio ambiente e percepção de lucros. Os cinco casos serão descritos seguindo a sequência das categorias analíticas mencionadas. 


\section{RESULTADOS DESCRIÇÃO DOS CASOS}

O caso 1 é um restaurante localizado na área rural, fundado e idealizado há 11 anos por dois sócios. Além do restaurante com capacidade para 250 pessoas, o empreendimento conta com vários atrativos de lazer junto à natureza, como: trilhas na mata, um centro naturista com tratamentos de saúde baseados na fitoterapia e na hidroterapia, passeios entre a horta e o pomar orgânico, lagos para pesca esportiva, interação com os animais da chácara, passeio de barco no lago e cavalgada. Além disso, tem um centro de reciclagem que visa à redução dos desperdícios e à geração de húmus para suas hortas e pomares. $\mathrm{O}$ entrevistado foi o dono e gestor do local, do sexo masculino, casado e com formação em direito. O estabelecimento possui três funcionários além entrevistado.

A ideia de montar o empreendimento surgiu após o falecimento dos avós do empreendedor, de origem polonesa. A família desejava restaurar a casa de arquitetura típica, manter a culinária praticada pelos antepassados e preservar a extensa área verde. Ao longo dos anos, o restaurante foi crescendo e as atividades de lazer se expandindo. O proprietário atribui o sucesso ao "boca a boca", pois os clientes iam recomendando o local para seus conhecidos, o que foi ampliando o número de clientes gradativamente. O entrevistado não possuía experiência anterior na função e relata: "aprendemos na prática mesmo, errando e acertando, sempre tentando fazer o nosso melhor" (Entrevistado 1).

Com relação ao impacto que o negócio tem na comunidade, o empreendedor disse que só contrata mão de obra local e dá preferência a fornecedores da região. Os produtos que adquire são em sua maioria da colônia, assim ajuda a comunidade e os produtores locais, que são valorizados. Já no que se refere ao meio ambiente, relata que a preservação da área de $250.000 \mathrm{~m}^{2}$ sempre esteve entre suas principais preocupações. Desde o início o negócio foi baseado em uma visão ecológica, cujos proprietários buscavam preservar a área verde e oportunizar para as pessoas da cidade a experiência de desfrutar da natureza de forma sustentável, diminuir o estresse do dia a dia e melhorar a conscientização em relação à conservação ambiental. Com o passar do tempo, além do restaurante e da área verde, foram acrescentados o centro de reciclagem, os passeios a cavalo, a chalana e os tratamentos de saúde alternativos. De acordo com o proprietário, a intenção é unir o benefício ecológico com o cultural (casa histórica/culinária típica) por meio do lazer e do turismo. Ao ser questionado em relação à importância do lucro no negócio, responde: "de zero a dez a importância do lucro para mim é dez, pois um negócio sem lucro não sobrevive muito tempo, acho que é por isso que nós estamos no mercado há mais de uma década" (Entrevistado 1).

A segunda empresa que participou do estudo é uma chácara dedicada à produção de alimentos orgânicos certificados, fundada e gerenciada por uma família. Além da produção de alimentos, o empreendimento oferece opções de ecoturismo, como: trilhas para caminhada 
na mata e passeios de bicicleta, palestras sobre o tema educação ambiental e eventos. A empreendedora conta que, no início, em meados dos anos 2000, a família desejava apenas se mudar para o meio rural e morar em um local tranquilo e com boa qualidade de vida. Ela era dona de casa e nunca havia empreendido. A agricultura começou inicialmente para consumo próprio, e por causa da preocupação com um consumo saudável, eles começaram a se interessar pelo cultivo orgânico. Aos poucos, amigos, conhecidos e vizinhos mostraram interesse no consumo das verduras e das frutas mais saudáveis e então a família começou a produzir mais para atender essa demanda, conforme relata entrevistada: "A medida que percebemos que o interesse das pessoas pelos alimentos orgânicos só aumentava e não era uma moda passageira, vislumbramos a oportunidade de investir no negócio para crescer e tornar toda nossa produção orgânica. Hoje estamos embasados por uma filosofia de agricultura ecologicamente correta"(Entrevistada 2).

Assim os proprietários investiram na propriedade e se qualificaram para conseguir se certificar e já possuem certificação pelo Tecpar, que garante a procedência dos alimentos e já produzem, além dos alimentos in natura, geleias, sucos e temperos. Além da produção, contam com serviços de entrega personalizada que atende a pessoas físicas, restaurantes e supermercados. Localizada em uma área com extensão de mais de sete mil alqueires, com muita floresta ao seu redor, a família empreendedora abriu o leque de atuação para a área do ecoturismo e criou um restaurante e uma infraestrutura de eventos para receber grupos. Atualmente recebe cerca de dois a três grupos por semana, oferecendo almoço e café colonial, além de atividades junto à natureza e esportes de aventura.

A entrevistada não tinha experiência anterior no negócio, mas foi se qualificando tecnicamente à medida que o empreendimento foi crescendo. Atualmente, além das 4 pessoas da família que trabalham no negócio, existem mais 3 funcionários contratados. Sobre a motivação da empreendedora em iniciar o negócio ela destaca: "Nós viemos morar no campo só pensando em ter um estilo de vida mais saudável, não imaginávamos que iria se tornar um negócio. Mas aos poucos fomos percebendo que tinha uma grande oportunidade na área de alimentos orgânicos e ecoturismo que não era atendida na região então investimos tudo o que tínhamos para fazer dar certo e deu" (Entrevistada 2). No que tange à importância do lucro, pontua como muito importante e atribui nota dez a este aspecto, mas também diz que a preservação da natureza é igualmente importante, pois sem a mesma não haveria possibilidade de um aproveitamento sustentável.

A terceira empresa é uma pousada ecológica, situada próximo a uma reserva ambiental de Mata Atlântica. Das empresas entrevistadas, essa é a que tem o acesso mais difícil, pois é feito por estrada de terra. Existem pouquíssimos empreendimentos no local, de modo que a pousada fica isolada de outros tipos de comércio. A empresa existe há 18 anos e foi fundada por um casal de empreendedores. A entrevistada foi a fundadora, tem 47 anos, é casada, possui ensino médio completo e reside no local. Além da empreendedora e do marido, trabalha na pousada uma funcionária. A pousada tem capacidade para 30 hóspedes, restaurante, SPA terapêutico, cachoeira natural, trilhas pela mata e escalada na montanha. Toda alimentação oferecida é vegetariana e orgânica produzida na própria pousada. A entrevistada relata que 
a ideia é oferecer um ambiente de cura e desintoxicação para os hóspedes, por isso não são servidas carnes nem bebidas alcoólicas ou industrializadas. A pousada também não tem TV, telefone ou outros tipos de tecnologia, pois como destaca a empreendedora, "o objetivo da pousada é que as pessoas venham para se conectar à natureza, relaxar e interagir com as outras pessoas através de vivências em grupo, não queremos que nenhuma tecnologia distraia nossos hóspedes neste processo" (Entrevistada 3).

A empreendedora não tinha experiência anterior na área e relata que foi influenciada por amigos que tinham uma chácara junto à natureza com quem conviviam. De início, ela e o marido idealizaram apenas um lugar em que eles pudessem estar longe da cidade grande, em harmonia com o meio ambiente. Aos poucos, o número de amigos e conhecidos a frequentar o local foi aumentando e veio a ideia de abrir a casa para o público, iniciando assim a pousada. Com o passar dos anos, eles foram ampliando, melhorando a estrutura física e atraindo mais visitantes. As épocas de maior movimento são os fins de semana e a temporada de verão. No restante do ano, a pousada oferece sua estrutura para terapeutas que levam seus pacientes para cuidados com a saúde física e mental, além de oferecer palestras e workshops para grupos. Neste empreendimento, destaca a entrevistada que a questão da preservação ambiental é essencial e esteve presente desde a sua criação, embora no início não houvesse intenção de atuar na área do ecoturismo. "No início eu e meu esposo sonhávamos em ter um espaço nosso, junto a natureza, de contemplação. As coisas foram evoluindo e nasceu a pousada, não foi algo planejado". (Entrevistada 3). A missão da pousada é propiciar a convivência em harmonia com a natureza, preservando a mata, a fauna e a flora. Ao ser perguntada sobre a importância do lucro financeiro com o empreendimento, ela comenta que "é a parte menos importante e atribui nota dois, pois durante todos esses anos, não houve foco na lucratividade e sim em manter o local funcionando e cumprindo sua missão".

O caso 4 consiste em uma loja de artesanato situada em uma região turística, uma colônia de imigrantes na região metropolitana de Curitiba. A loja existe há 5 anos e foi fundada pela própria empreendedora, que tem 58 anos, é casada, formada em Pedagogia e aposentada do setor público. Ela é a única a atender os clientes, mas nos dias de maior movimento conta com a ajuda do marido para fazer o atendimento. Ela relata que produz as peças, feitas de fibra natural e outros materiais recicláveis em seu ateliê em casa durante a semana, quando a loja está fechada e atende as centenas de turistas que visitam o local durante os fins de semana e feriados, quando a loja está aberta. A entrevistada relata que sempre sonhou em viver de artesanato. Ela era professora em Curitiba e, após a aposentadoria, queria empreender. Um dia foi visitar a colônia como turista e gostou muito. Foi tão bem recebida pela comunidade que vendeu tudo que tinha em Curitiba e comprou uma casa lá com espaço para o Ateliê e alugou uma loja de fácil acesso aos turistas. Ao longo de cinco anos, foi crescendo. Os clientes que visitam o restaurante próximo acabam visitando a loja, principalmente enquanto aguardam por mesas. Atualmente ela já pensa em contratar uma funcionária, pois conta que não está dando conta de produzir as peças, entregar encomendas e também atender na loja.

A empreendedora não tinha experiência anterior nesta atividade, mas a mãe era artesã e desde criança ela fazia artesanato. Durante sua carreira como professora, a arte era 
apenas um hobby, mas ela já sonhava em ter uma loja. Outra experiência anterior que a auxiliou muito foi o fato de ter dado muitos cursos de atendimento ao cliente durante sua carreira. Ela acredita que esse conhecimento foi fundamental e o ajuda hoje. Além disso ela fez muitos cursos no Sebrae para se preparar e se sentir pronta para empreender, assim que conseguisse a aposentadoria. Quando perguntada sobre o impacto de sua atividade para o meio ambiente, ela responde: "a reciclagem é fundamental para a preservação do nosso planeta. Às vezes as pessoas pensam que eu simplesmente reciclo os produtos transformando em uma peça de artesanato e que uma garrafa de plástico reciclada é pouco para a natureza. Mas a peça é adquirida por alguém que ia comprar algo industrializado como lembrança e acaba adquirindo uma peça sustentável, feito por uma artesã local e que vai dar de presente para outro alguém e estimular essa consciência (...) É um ciclo virtuoso" (Entrevistada 4).

Sobre a motivação da empreendedora em iniciar o negócio, ela conta que sempre sonhou em ter um negócio próprio, que pudesse ser compatível com seu estilo de vida, com uma alimentação mais saudável e junto à natureza. Quando conheceu a região, achou o lugar perfeito para realizar este sonho. Ela acredita que seu trabalho faz parte de uma missão de vida que inclui o incentivo à preservação da natureza e à conscientização das pessoas para uma nova era, um novo tempo em que humanos e natureza viverão em harmonia. Ao ser questionada o quanto em uma escala de zero a dez era importante para ela obter lucro no negócio, ela responde: "digamos que cinco, pois já tenho o rendimento da minha aposentadoria. Os lucros no artesanato não são muito grandes e minha produção é pequena, então se o caixa estiver positivo e sobrar um pouquinho já está satisfatório, pois vou continuar fazendo o que gosto" (Entrevistada 4).

\section{CASO 5}

O quinto caso é uma agência de ecoturismo, fundada por duas irmãs que administram o negócio. A entrevistada foi a irmã mais jovem, que tem 42 anos e é casada. Além das duas irmãs sócias, trabalham na empresa mais 2 funcionários. A empresa existe há 8 anos e atua como agência de viagens com foco em venda de pacotes de viagens ecológicos nacionais e internacionais. Atende tanto a clientes particulares quanto a corporativos. A entrevistada explica como surgiu a ideia de empreender: "surgiu pelo desejo de ter algo próprio e vimos um nicho de mercado a ser explorado - passeios ecológicos". (Entrevistada 5). Entretanto, após algum tempo, começaram a oferecer também outros tipos de viagens para ampliar o portfólio da empresa. A entrevistada não tinha experiência direta e nem formação voltada para a atividade, conforme ela relata: "Sou nutricionista e isso não me ajudou em nada, mas minha irmã e sócia é bióloga e isso ajudou muito na hora de montar os roteiros ecológicos" (Entrevistada 5). De acordo com a empreendedora, o maior motivador para iniciar o negócio foi o desejo de ter um negócio próprio, de poder fazer os próprios horários e tomar as próprias decisões em relação a seu futuro profissional. O início do negócio não foi baseado somente na questão ecológica, entretanto as sócias se preocupam com as questões ambientais e desejam que sua atividade contribua para a preservação do meio ambiente. Ela pontua a importância do lucro no negócio na escala de zero a dez como sendo extremamente importante, com nota dez, pois a empresa é responsável pelo sustento da família, portanto a proprietária está sempre se esforçando para aumentar a lucratividade do negócio. 


\section{ANÁLISE COMPARATIVA DOS CASOS}

Com relação às caraterísticas das empresas, observa-se que, com exceção da loja de artesanato, que não possui funcionários contratados, as demais empresas possuem dois e três funcionários. De acordo com Pimentel et al. (2013), desde a regulamentação da Lei Complementar 123/2006 percebe-se um esforço em termos de políticas públicas para o incremento das micro e pequenas empresas, o que vem contribuindo para a formalização do empreendedor. Segundo o autor, este cenário beneficiou as atividades ligadas à cadeia do turismo e suas oportunidades de expansão. Das empresas estudadas, três encontram-se enquadradas como "Simples Nacional", ou seja, possuem limites anuais de faturamento de R\$4,8 milhões, enquanto as empresas enquadradas como Microempreendedor Individual (MEI) possuem limites anuais de R\$ 81 mil (RECEITA FEDERAL, 2017). Somente a pousada e a loja de artesanato estão enquadradas no $\mathrm{MEI}$, de modo que o faturamento das outras 3 empresas entrevistadas é maior. Outro dado que se destaca é o tempo de fundação das empresas. Quase todas estão funcionando há mais de uma década e mostram constante crescimento. Este dado encontra consonância na literatura, em que vários autores citam que o ecoturismo teve um desenvolvimento rápido na última década, refletindo o desejo das pessoas de se manter em contato com a natureza (Koch, Junqueira \& Anjos, 2017; Swan \& Morgan, 2016). O progresso dos ecoempreendedores pesquisados pode estar ligado à ações públicas mais especificamente realizadas na região metropolitana de Curitiba, no estado do Paraná, conforme cita o estudo de Silveira (2005). Desde o ano de 1998 foi iniciada a implantação de projetos de turismo em escala local, como o chamado "Anel de Turismo", que conectou governo, município e empreendedores locais. Destes, o turismo rural e o ecoturismo são as duas principais modalidades mais incentivadas na região. Esse fator pode ter tido impacto na longevidade das empresas entrevistadas. O Quadro 1 apresenta um resumo das características das empresas estudadas:

\begin{tabular}{|l|l|l|l|l|}
\hline & Setor de atividade & $\begin{array}{l}\text { Número de } \\
\text { empregados }\end{array}$ & $\begin{array}{l}\text { Tempo de } \\
\text { atuação }\end{array}$ & $\begin{array}{l}\text { Categoria de } \\
\text { Empresa }\end{array}$ \\
\hline Caso 1 & Restaurante & 3 & 11 anos & Simples Nacional \\
\hline Caso 2 & $\begin{array}{l}\text { Produção de orgânicos e atividades de } \\
\text { ecoturismo }\end{array}$ & 3 & 17 anos & Simples Nacional \\
\hline Caso 3 & Pousada & 1 & 18 anos & MEI \\
\hline Caso 4 & Loja de artesanato & Não possui & 5 anos & MEI \\
\hline Caso 5 & Agência de ecoturismo & 2 & 8 anos & Simples Nacional \\
\hline
\end{tabular}

Quadro 1. Características das empresas

Fonte: Elaborado pelas autoras

Com relação ao perfil dos entrevistados, constata-se nesse estudo que não possuíam formação em turismo, mas nas áreas mais diversas do conhecimento: direito, nutrição, pedagogia, entre outros. Esses achados estão em consonância com um estudo anterior de Teixeira (2012), que pesquisou a criação de novos negócios em turismo em Curitiba, PR e encontrou que a maioria dos negócios estudados iniciou informalmente a partir de empreendedores que não detinham informações aprofundadas do setor. 
Os empreendedores pesquisados no presente estudo relatam que adquiriram experiência na prática do negócio, embora alguns, como a dona da loja de artesanato e o dono do restaurante, relataram que o conhecimento anterior os ajudou de forma indireta a tocar o negócio. No que tange ao reconhecimento de seu empreendimento como tendo um impacto para o meio ambiente, todos são unânimes em afirmar que a empresa atua de forma positiva para preservar a natureza e se utiliza de práticas sustentáveis. Assim, os entrevistados se mostraram ecologicamente conscientes em relação ao papel de suas empresas no meio ambiente, embora, não necessariamente, o ecoempreendedor, para ser considerado como tal, deve estar imbuído desta consciência (Hoogendoorn, Guerra, \& Van der Zwan, 2015, Fonseca, Silva, Santos \& Leite, 2015).

Ainda em relação à composição do negócio, observa-se a participação de membros da família atuando. Tanto a pousada, o restaurante e a chácara foram iniciadas a partir do sonho de um casal, e ainda hoje se mantêm com os membros da família atuando no negócio. Já a agência de turismo foi fundada por duas irmãs. A loja de artesanato, embora idealizada pela artesã, conta com a ajuda do marido no atendimento aos clientes. Uma explicação para este achado pode ser o desejo declarado dos entrevistados de criar um negócio que permitisse uma melhor qualidade de vida e equilíbrio entre as relações familiares. No caso do restaurante, além disso, havia o desejo de manter a cultura, a gastronomia e as tradições da terra natal de seus ascendentes, com a restauração da casa de arquitetura típica e manutenção de objetos históricos. O quadro 2 apresenta perfil dos ecoempreendedores da pesquisa.

\begin{tabular}{|l|l|l|l|l|}
\hline & Idade & Estado civil & Experiência na atividade & Escolaridade/ Área \\
\hline Caso 1 & 29 & Casado & Não possuía & Superior - Direito \\
\hline Caso 2 & 63 & Casada & Não possuía & Ensino médio \\
\hline Caso 3 & 47 & Casada & Não possuía & Ensino médio \\
\hline Caso 4 & 58 & Casada & Não possuía & Superior- Pedagogia \\
\hline Caso 5 & 42 & Casada & Não possuía & Superior - Nutrição \\
\hline
\end{tabular}

Quadro 2.Perfil dos Ecoempreendedores

Fonte: Elaborado pelas autoras

No que se refere à categoria analítica ecossustentabilidade no negócio (Borges et al., 2013, Pereira, 2013), os casos enquadram-se na categoria turismo de lazer e natureza, sendo que a chácara de orgânicos acumula também a categoria de agricultura orgânica e extrativismo, que, no caso, foi sua primeira opção de empreendimento, tendo o ecoturismo surgido mais tarde. Já a loja de artesanato acumula a categoria reciclagem e reutilização, por se tratar de artesanato com peças recicladas, de acordo com o Quadro 3.

\begin{tabular}{|l|l|l|}
\hline & Empresa & Categorias de ecossustentabilidade \\
\hline Caso 1 & Restaurante & Turismo e lazer na natureza \\
\hline Caso 2 & Chácara de Orgânicos e Ecoturismo & Turismo e lazer na natureza/ agricultura orgânica \\
\hline Caso 3 & Pousada & Turismo e lazer na natureza \\
\hline Caso 4 & Loja de artesanato & Turismo e lazer na natureza/reciclagem e reutilização \\
\hline Caso 5 & Agência de ecoturismo & Turismo e lazer na natureza \\
\hline
\end{tabular}

Quadro 3. Categorias de Ecossustentabilidade presentes no negócio

Fonte: Elaborado pelas autoras 
Com o objetivo de classificar os empreendedores com base no modelo de tipologias de Walley \& Taylor (2002), foi perguntado aos entrevistados sua principal motivação para empreender e, a seguir, comparada a descrição de categorias dos autores. Um resumo das tipologias com as motivações principais dos empreendedores encontra-se no Quadro 4.

\begin{tabular}{|l|l|l|l|}
\hline & Empresa & Motivação principal & Tipologia \\
\hline Caso 1 & Restaurante & $\begin{array}{l}\text { Preservar a área verde e oportunizar para as pessoas da cidade } \\
\text { a experiência de desfrutar da natureza, longe do estresse da } \\
\text { cidade grande. }\end{array}$ & Ethical Maverick \\
\hline Caso 2 & $\begin{array}{l}\text { Chácara de } \\
\text { Orgânicos e } \\
\text { Ecoturismo }\end{array}$ & $\begin{array}{l}\text { Ter um estilo de vida mais saudável, no início não tinham } \\
\text { intenção de montar um negócio, mas vislumbraram a } \\
\text { oportunidade e investiram. }\end{array}$ & Ethical Maverick \\
\hline Caso 3 & Pousada & $\begin{array}{l}\text { De início, idealizaram apenas um lugar em que eles pudessem } \\
\text { estar longe da cidade grande, em harmonia com o meio } \\
\text { ambiente, foram influenciados por amigos. }\end{array}$ & Ethical Maverick \\
\hline Caso 4 5 & $\begin{array}{l}\text { Loja de } \\
\text { artesanato }\end{array}$ & $\begin{array}{l}\text { Acredita que seu trabalho faz parte de uma missão de vida que } \\
\text { inclui o incentivo à preservação da natureza, além de manter } \\
\text { seu estilo de vida. }\end{array}$ & $\begin{array}{l}\text { Visionary } \\
\text { Champion e } \\
\text { Ethical Maverick }\end{array}$ \\
\hline Eesejurismo & $\begin{array}{l}\text { Desejo de ter um negócio próprio, vislumbraram um nicho de } \\
\text { mercado desatendido para ser explorado. }\end{array}$ & $\begin{array}{l}\text { Ad Hoc } \\
\text { Enviropreneur }\end{array}$ \\
\hline
\end{tabular}

Quadro 4. Tipologias dos ecoempreendedores

Fonte: Elaborado pelas autoras

Pode-se observar que três dos entrevistados correspondem ao tipo Ethical Maverick, que possuem forte direcionamento para a sustentabilidade e baixa motivação para mudar as estruturas. No caso da loja de artesanato, pode-se enquadrá-la em duas categorias, já que, além de possuir as características do Ethical Maverick, ela também corresponde às características do Visionary Champion, isto é, além de utilizar o negócio para manter seu estilo de vida, a empreendedora deseja mudar as estruturas por meio da conscientização das pessoas. Por outro lado, a agência de turismo ajusta-se à definição de Ad Hoc Enviropreneur, uma vez que entrou no negócio quase por acidente, ao perceber uma oportunidade não explorada por outras agências e que estava em amplo crescimento na época da fundação da empresa.

Em relação à importância atribuída à lucratividade no negócio, observou-se que apenas a dona da pousada não considera o lucro como fundamental para a sobrevivência do negócio. Em seu discurso, ela pontua que nunca teve a intenção de acumular capital por meio do negócio, ao contrário, desde o início a ideia foi viver com simplicidade, junto à natureza e que o lucro gerado sempre foi reinvestido no negócio, a fim de preservar a propriedade e o seu estilo de vida. Constata-se que, no restaurante, na chácara de orgânicos/ ecoturismo e na agência de ecoturismo a questão da lucratividade é muito importante, tendo recebido peso máximo e está inclusive relacionada ao sustento dos empreendedores e de suas famílias. Já a loja de artesanato não é a única fonte de renda da empreendedora, que é aposentada de outra função e talvez por esta razão ela tenha atribuído uma nota média de cinco, ficando evidente que a existência do negócio está mais relacionada à sua satisfação com a atividade e valores pessoais que pratica como uma missão de vida.

De forma geral, independente da nota atribuída à lucratividade, todos os entrevistados mostraram-se com alto nível de consciência em relação ao impacto de seus empreendimentos 
no meio ambiente. Os achados deste estudo corroboram com os de Allen \& Malin (2008), que estudaram casos de pequenos empreendedores verdes e Silajdzic, Kurtagic, \& Vucjakjak (2015), que destacaram em sua pesquisa a forte conexão entre os ecoempreendedores e seus valores pessoais. A questão dos valores verdes fica bastante evidente nos discursos e também na origem dos empreendimentos, conforme relatado pelos entrevistados e sugerido também em diversos estudos no tema (Gibbs, 2009; Kirkwood \& Walton, 2010, Schaltegger, 2002, Swan \& Morgan, 2016).

Deste modo, os resultados da presente pesquisa apontam para o esforço dos ecoempreendedores em expandir a preocupação ecológica de seu negócio e englobar outras formas de diminuir o impacto negativo de sua atuação por meio da preocupação com o consumo de água responsável, reciclagem do lixo, não utilização de agrotóxicos e busca de utilização de fontes de energia renovável, por exemplo. O aumento desta preocupação no setor hoteleiro e alimentício do turismo também foi descrito por Iraldo et al. (2017) em um estudo recentemente realizado na Itália, o que sugere que a preocupação com a preservação da natureza e a sustentabilidade no setor são uma tendência mundial.

Pode-se perceber também que, no caso da pousada, da loja de artesanato e da chácara de orgânicos, os empreendedores iniciaram suas atividades voltadas ao turismo na natureza sem grandes motivações de preservação, mas que, com o passar do tempo, foram desenvolvendo uma consciência ecológica maior e os negócios foram se voltando ao ecoturismo. Nesses casos, a preocupação dos empreendedores em realizar o mínimo impacto junto à natureza é bastante forte e foi aumentando com o tempo, fazendo-se presente de diversas formas, como na alimentação, na utilização dos recursos e na reciclagem. Tais resultados acrescentam algo novo no estudo do campo, pois sugerem que empreendedores que iniciam atuando na área do turismo na natureza ou rural acabam desenvolvendo uma consciência ecológica maior ao longo do tempo e focando seu negócio no ecoturismo a partir do desenvolvimento de uma necessidade não antes atentada de preservação do meio e preocupação com a sustentabilidade.

Observa-se ainda nesta pesquisa que as evidências estão em consonância com os achados de outros autores que estudaram os ecoempreendedores, seu perfil e motivação (Isaak, 1998, Kirkwood \& Walton, 2010, Linnanen, 2002, Walley \& Taylor, 2002). Os maiores motivadores relacionados em estudos anteriores foram ganhar dinheiro e ao mesmo tempo contribuir para a preservação da natureza (Isaak, 1998, Kirkwood \& Walton, 2010).

A utilização da ferramenta de pesquisa de tipologias de Walley \& Taylor (2002), associada às entrevistas realizadas, mostrou-se eficaz para revelar as principais motivações dos ecoempreendedores para se engajar no setor de turismo na natureza. Desta forma, o objetivo geral do estudo foi atingido ao apresentar as características dos ecoempreendedores na área, revelar suas histórias de atuação e, não menos importante, a forma como percebem o papel do lucro em seus negócios. Como se pode observar, os empreendedores estudados não apresentaram contradições em relação à preservação do meio ambiente e ao impacto de sua atuação com a motivação de obtenção de lucro. Ao contrário, observou-se que os empresários conciliam de forma profícua e equilibrada esses dois estímulos a julgar-se, principalmente, que estão atuando neste mercado há mais de uma década em sua maioria. Deste modo, pode-se dizer que seus negócios são duradouros e que estão atingindo os objetivos a que se propõem. 
Acredita-se que estas descobertas possam auxiliar em novos estudos sobre quem é o ecoempreendedor atuante na área de turismo, porque decidem iniciar e manter seus negócios, como administram as motivações econômicas e ecológicas envolvidas e que aspectos influenciam na longevidade de seus negócios. Outro aspecto importante levantado nos achados diz respeito à questão da relação entre o tempo de início do negócio na área do turismo na natureza e sua relação com o amadurecimento do empreendedor ao longo dos anos para uma consciência e postura mais ecológica. Isto pode levá-lo a redirecionar o foco de atuação de seu negócio para o ecoturismo em si, ao praticar modalidades mais sustentáveis de turismo. Essa relação de fatores merece ser mais bem explorada e estudada.

\section{CONSIDERAÇÕES FINAIS}

Os achados deste estudo demonstram que um novo tipo de empreendedor com motivações tanto ecológicas quanto econômicas está surgindo, contrariando a visão clássica do empreendedor, cuja principal preocupação era apenas o retorno financeiro do negócio. Este novo empreendedor é capaz de combinar a motivação econômica com a motivação ecológica e ambiental, tornando as ações ecológicas como parte da própria lógica de seus negócios. Além disso, sua vivência e experiência no negócio, com o passar do tempo, parecem influenciar sua consciência ecológica de modo que eles acabam desenvolvendo maior comprometimento com a conservação do meio ambiente e proteção das regiões em que atuam.

Isto pôde ser observado por meio da análise da motivação dos entrevistados para abrir e manter o negócio. Três deles demonstraram que a principal motivação para abrir seu negócio foi a manutenção de seu estilo de vida, bem como uma forte orientação à sustentabilidade. Estes seriam os chamados Ethical Mavericks, conforme a tipologia utilizada como referência neste estudo (Walley \& Taylor, 2002). Um dos entrevistados pode ser considerado como Ad hoc Enviropreneur, já que a decisão de iniciar o negócio foi acidental e sua motivação é fortemente financeira. Por outro lado, uma das empreendedoras entrevistada pode ser considerada uma Visionary Champion, pois possui forte orientação sustentável, associada ao desejo de mudar o mundo, espalhando sua visão de sustentabilidade. Embora se tenha encontrado que os valores verdes estão presentes em todos os ecoempreendedores analisados, a motivação financeira em relação ao negócio também foi um forte determinante encontrado. Isso demonstra que este tipo de empreendedor consegue conciliar de forma equilibrada suas inclinações financeiras com as ecológicas.

Além disso, a pesquisa apontou para questões pouco exploradas na literatura, como a mudança de percepção do empreendedor em relação à preservação do meio natural, que acontece mesmo quando a motivação inicial consistia apenas na manutenção de uma chácara rural ou na aquisição de um terreno para passar os fins de semana. Sugere-se que estudos futuros aprofundem para compreensão dessas motivações. Além disso, sugerem-se estudos em outras regiões no Brasil para fins de comparação de resultados.

Emboraosachadosdesteestudoestejam limitadosacincocasosdeecoempreendedores e não possam ser generalizados, essas experiências comuns acrescentam valor para a compreensão de seus comportamentos, motivações e podem orientar a direção de futuros estudos. As pesquisas sobre empreendedorismo verde e econegócios são importantes 
e necessárias para explorar o papel dos empreendedores que criam seus negócios, com objetivo de atuar em um ecossistema sustentável, ao mesmo tempo que provêm ganhos econômicos e sociais que beneficiam toda a sociedade.

\section{REFERÊNCIAS}

Allen, J. C., \& Malin, S. (2008) Green Entrepreneurship: A Method for Managing Natural Resources? Society \& Natural Resources, 21(9), 828-844.

Anderson, A. R. (1998). Cultivating the garden of eden: environmental entrepreneuring. Journal of Organizational Change Management, 11(2), 135-44.

Anup, K. C., Rijal, K., \& Sapkota, R. P. (2015) Role of ecotourism in environmental conservation and socioeconomic development in Annapurna conservation area, Nepal. International Journal of Sustainable Development and World Ecology, 22(3), 251-258. https://doi.org/10.1080/13504509. 2015.1005721

Asadi, A., \& Kohan, M. F. Z. (2011) The role of Entrepreneurship on Ecotourism development. Sociality and Economics Development, 10, 38-42.

Bardin, L. (2011) Análise de Conteúdo. São Paulo: Edições 70.

Bob McKercher (2002) Turismo de natureza: planejamento e sustentabilidade. Contexto

Borges, C., Borges, M. M., Ferreira, V. da R. S., Najberg, E., \& Tete, M. F. (2013) Empreendedorismo sustentável: proposição de uma tipologia e sugestões de pesquisa. Revista de Empreendedorismo e Gestão de Pequenas Empresas, 2(1), 77-100.

Bosetti, C. \& Oliveira, V. P. (2016) Ecoturismo e o turismo rural como estratégia de desenvolvimento sustentável: um estudo em propriedades rurais da região da Amauc/SC. Ágora, 21(1), 43-63.

Boszczowski, A. K. \& Teixeira, R. M. (2012) O empreendedorismo sustentável e o processo empreendedor: em busca de oportunidades de novos negócios como solução para problemas sociais e ambientais. Economia \& gestão, 12(29), 141-168.

Brumatti, P. N. M. (2014) Sociedade, cultura e natureza: influências do ambientalismo no desenvolvimento do ecoturismo. Caderno Virtual de Turismo, 14(3), 280-297.

Brunelli, M. \& Cohen, M. (2012) Definições, Diferenças e Semelhanças entre Empreendedorismo Sustentável e Ambiental: Análise do Estado da Arte da Literatura entre 1990 e 2012. XXXVI Encontro Da ANPAD, 1-16. Retrieved from http://www.anpad.org.br/ anpad/abrir_pdf.php?e=MTQ4MDM=

Budeanu, A., Miller, G., Moscardo, G., \& Ooi, C.-S. (2016) Sustainable tourism, progress, challenges and opportunities: an introduction. Journal of Cleaner Production, 111, 285-294. https://doi. org/10.1016/j.jclepro.2015.10.027

Creswell, J. W. (2010) Projeto de Pesquisa: Métodos Qualitativo, Quantitativo e Misto. Porto Alegre: Artmed.

Dana, L. (1995) Entrepreneurship in a Remote Sub- Artic Community. Entrepreneurship Theory and Practice, 20(1), 57-72.

Dixon, S. E. A. \& Clifford, A. (2007a). Ecopreneurship - a new approach to managing the triple 
bottom line. Journal of Organizational Change Management, 20(3), 326-345. https://doi. org/10.1108/09534810710740164

Dixon, S. E. A. \& Clifford, A. (2007b). Ecopreneurship - a new approach to managing the triple bottom line. Journal of Organizational Change Management, 20(3), 326-345. https://doi. org/10.1108/09534810710740164

Donohoe, H. M. \& Needham, R. D. (2006) Ecotourism: The Evolving Contemporary Definition. Jounal of Ecotourism, 5(3), 192-210.

Eisenhardt, K. M. (1989) Building Theories from Case Study Research. Academy of Management Review. https://doi.org/10.5465/AMR.1989.4308385

Elmuti, D., Abebe, M., \& Nicolosi, M. (2005) An overview of strategic alliances between universities and corporations. Journal of Workplace Learning. https://doi.org/10.1108/13665620510574504

Fonseca, S. M., Da Silva, A. P., Santos, D. D. C. L., \& Leite, E. F. (2015) Ecoempreendedorismo E Competências Empreendedoras: O Caso Ecoempreendedor Transformador De Resíduo Em Riqueza. Holos, 2, 183. https://doi.org/10.15628/holos.2015.2367

Galvão, J. (2004) O Processo De Planejamento Do Turismo De Natureza : Reflexões Sobre a Construção Da Política Municipal De Desenvolvimento Sustentável do Turismo De Brotas. Tese de Mestrado - UNESP.

Gast, J., Gundolf, K., \& Cesinger, B. (2017) Doing business in a green way: A systematic review of the ecological sustainability entrepreneurship literature and future research directions. Journal of Cleaner Production, 147, 44-56. https://doi.org/10.1016/j.jclepro.2017.01.065

Gibbs, D. (2009) Sustainability Entrepreneurs, Ecopreneurs and the Development of a Sustainable Economy. Greener Management International, 55, 63-79.

Godoi, C. K., Bandeira-de-Melo, R., \& Silva, A. B. da. (2006) Pesquisa qualitativa em estudos organizacionais: Paradigmas, Estratégias e Métodos. São Paulo: Saraiva.

Gorni, P. M., \& Dreher, M. T. (2010) Estratégias Intersetoriais no Desenvolvimento do Turismo de Natureza: desafios e perspectivas. Revista Turismo Em Análise, 21(3), 567-593.

Hall, J. K., Daneke, G. A., \& Lenox, M. J. (2010) Sustainable development and entrepreneurship: Past contributions and future directions. Journal of Business Venturing, 25(5), 439-448. https://doi. org/10.1016/j.jbusvent.2010.01.002

Hoogendoorn, B., Guerra, D., \& van der Zwan, P. (2015) What drives environmental practices of SMEs? Small Business Economics, 44(4), 759-781. https://doi.org/10.1007/s11187-014-9618-9

Isaak, R. (1998) Green Logic: Ecopreneurship, Theory and Ethics. Sheffield: Greenleaf Publishing.

Isaak, R. (2002) The Making of the Ecopreneur. Green Management International, 38, 81-91.

Jones, G. G., \& Spadafora, A. (2016) Entrepreneurs and the Co-Creation of Ecotourism in Costa Rica.

Kirkwood,J., \&Walton,S.(2010)Whatmotivatesecopreneurstostartbusinesses? InternationalJournalof Entrepreneurial Behavior \& Research, 16(3), 204-228. https://doi.org/10.1108/13552551011042799

Koch, P. O. M., Junqueira, L. D. M., \& Anjos, F. A. (2017) Análise comparativa do turismo sustentável 
e turismo responsável : semelhanças e diferenças nos destinos turísticos do Brasil. Caderno de Estudos e Pesquisas Do Turismo, 6(9), 39-56.

Koe, W. L., \& Majid, I. A. (2014) Socio-Cultural Factors and Intention towards Sustainable Entrepreneurship. Eurasian Journal of Business and Economics, 7(13), 145-156.

Linnanen, L. (2002) An Insider's Experiences with Environmental Entrepreneurship. Greener Management International, 38(38), 71-80. https://doi.org/10.9774/GLEAF.3062.2002.su.00008

Lordkipanidze, M., Brezet, H., \& Backman, M. (2005) The entrepreneurship factor in sustainable tourism development. Journal of Cleaner Production, 13(8), 787-798. https://doi.org/10.1016/j. jclepro.2004.02.043

Mendonça, R., \& Neiman, Z. (2002) Ecoturismo: discurso, desejo e realidade. ... Ambiente, Educação E Ecoturismo. ..., 11(2), 1-14. Retrieved from http://www.institutoroma.org.br/artigos/ ecoturismo_desejo_e_realidade.pdf

Mieszajkina, E. (2016) Ecological Entrepreneurship and Sustainable Development Przedsiębiorczość ekologiczna a rozwój zrównoważony Elena Mieszajkina. Problems of Sustainable Development, 12(1), 163-171.

Ministério do Turismo. www.turismo.gov.br/. Acesso em 02/02/2018.

Moura da Fonseca, S. M., Da Silva, A. P., E Penalva Santos, D. D. C. L., \& Leite, E. F. (2015) Ecoempreendedorismo E Competências Empreendedoras: O Caso Ecoempreendedor Transformador De Resíduo Em Riqueza. Holos, 2, 183. https://doi.org/10.15628/holos.2015.2367

Parrish, B. (2010) Sustainability-driven entrepreneurship: Principles of organization design. Journal of Business Venturing, 25(5), 510-523.

Pastakia, A. (1998) Grassroots ecopreneurs: change agents. Journal of Organizational Change Management Grassroots, 11(2), 157-173.

Pereira, T. S. (2013) Empreendedorismo sustentável em regiões turísticas de Goiás. Revista Brasileira de Ecoturismo, 6(3), 758-777.

Pimentel, A., Violento, A., Rodrigues, C. G. D. O., Julião, D. P., Juer, E., \& Lohmann, J. B. (2013) Empreendedorismo e formalização de atividades de turismo em ambientes naturais. Revista Acadêmica Observatório de Inovação Do Turismo, 7(4), 29.

Prochnow, W. E. \& Vasconcelos, E. C. De. (2008) O estado-da-arte das ações para certifi cação em ecoturismo. Caderno Virtual de Turismo, 8(3), 29-40.

Receita Federal. http://idg.receita.fazenda.gov.br/. Acesso em 02/02/2018.

Schaltegger, S. (2002) A Framework for Ecopreneurship. Green Management International, 38(Summer), 45-59. https://doi.org/10.9774/GLEAF.3062.2002.su.00006

Schaltegger, S. \& Wagner, M. (2011) Sustainable Entrepeneurship and Sustainability Innovation: Categories and Interactions. Business Strategy and Environment, 20(4), 222-237. https://doi. org/10.1002/bse.682

Shepherd, D. A. \& Patzelt, H. (2011)ET \& PThe New Field of Entrepreneurship :Sustained" With "What Is to Be Developed." Entre, 35(1), 137-163. https://doi.org/10.1111/j.1540-6520.2010.00426.x 
Silajdzic, I., Kurtagic, S. M., \& Vucjakjak, B. (2015) Green entrepreneurship in transition economies: A case study of Bosnia and Herzegovina. Journal of Cleaner Production, 88, 376-384. https://doi. org/10.1016/j.jclepro.2014.07.004

Silveira, M. A. T. (2005) Turismo e estratégias de desenvolvimento local Tourism and strategies of local development Turismo y estrategias de desarrollo local. Interações, 7(11), 129-140.

Spaolonse, E. \& Oliveira, S. De. (2017) Ecoturismo : uma ponte para o turismo sustentável. Revista Brasileira de Ecoturismo, 9(6), 684-698.

Swan, C. D. \& Morgan, D. (2016) Who wants to be an eco-entrepreneur? Identifying entrepreneurial types and practices in ecotourism businesses. International Journal of Entrepreneurship and Innovation, 17(2), 120-132.

Teixeira, R. M. (2012) O Processo de Criação de Novos Negócios em Turismo : estudo de casos múltiplos em agências de viagens em Curitiba, Paraná, 23, 464-483.

Thompson, J. L. (1999) The world of the entrepreneur: a new perspective. Journal of Workplace Learning, 11(6), 209-224.

Viana, F. C. \& Nascimento, M. A. L. (2009) O turismo de natureza como atrativo turístico do município de Portalegre, Rio Grande do Norte. Pesquisas Em Turismo e Paisagens Cárticas, 2(1), 79-96.

Walley, E. E. L. \& Taylor, D. W. D. (2002) Opportunists, Champions, Mavericks...? Green Management International, 38, 31-43.

World Tourism Organization UNWTO. www2.unwto.org/content/why-tourism. Acesso em 02/02/2018.

York, J., \& Venkataraman, S. (2010) The entrepreneur-environment nexus: Uncertainty, innovation, and allocation. Journal of Business Venturing, 25(5), 449-463.

Contribuições de cada autor:

Vivien Kaniak: Introdução, Revisão de literatura, Coleta de dados, Análise de dados, Conclusão.

Rivanda Meira Teixeira: Revisão do artigo: Introdução, Revisão de literatura, Análise de dados, Conclusão. 